\title{
A geochemist's perspective on the pace, magnitude, and drivers of sea-level change
}

\author{
ANDREA DUTTON ${ }^{1}$
}

${ }^{1}$ Department of Geoscience, University of Wisconsin-

Madison, 1215 Dayton St., Madison, WI, 53706

The dynamics of past climate and sea-level change provides important benchmarks for models that are used to project future sea-level rise. U-Th dating of fossil corals and speleothems has played a key role in establishing a temporal framework for the absolute timing and rate of past sea-level changes on glacial-interglacial timescales. On one hand, technological advances have improved the precision of our analytical tools, enabling us to ask different questions and push the boundaries of temporal and spatial resolution. On the other hand, dating fossil corals poses a number of challenges including factors that affect age determination as well as uncertainties in interpreting paleowater depth and inferring global sea-level from site-specific reconstructions. In seeking to refine our understanding of past sea-level change in both space and time we have faced a number of obstacles as a community - some of them analytical or geochemical in nature, while others require interdisciplinary partnerships. I will summarize some of the approaches to overcoming these hurdles by considering how our understanding of Last Interglacial sea level has evolved through time and how our existing knowledge as well as future research efforts are relevant to understanding the timing, magnitude and nature of future sea-level rise. 